In conclusion, the $\mathrm{Sn} / \mathrm{Au}$ thin-film system provides an example of Kirkendall-type effects in which both species can diffuse rapidly into each other, but via different diffusion mechanism. Similar observations have been recently made on the $\mathrm{Cu} / \mathrm{Pb}$ system by Campisano et al. ${ }^{11}$ This study illustrates the fact that several competing diffusion mechanisms can exist in thin-film systems. Thus assessment of the relative importance of each mechanism requires careful attention to relative film thickness, film geometry, and grain sizes.

We would like to thank L. B. Hooker for his careful sample preparation.
B. Selikson, Appl. Phys. Lett. 14, 283 (1969).

A. D. Smigelskas and E. O. Kirkendall, Trans. AIME 171, 130 (1947).

'I. A. Blech and H. Sello, J. Electrochem. Soc. 113, 1052 (1966)

${ }^{\dagger}$ J. R. Lloyd and S. Nakahara, Thin Solid Films 54, 207 (1978)

B. F. Dyson, J. Appl. Phys. 37, 2375 (1966)

${ }^{\prime} \mathrm{C}$. Herzig and T. Heumann, Z. Naturforsch. 27a, 1109 (1972)

'S. Nakahara and R. J. McCoy, Thin Solid Films (to be published).

${ }^{\mathrm{M}} \mathrm{M}$. Hansen and K. Anderko, Constitution of Binary Alloys (McGraw-Hill,

New York, 1958), p. 233.

"V. Simić and Z. Marinković, J. Less Comm. Met. 51, 177 (1977).

"'L. Buene, Thin Solid Films 47, 159 (1977).

'S. U. Campisano, E. Costanzo, and E. Rimini, Philos. Mag 35, 1333

(1977).

\title{
Confining substrate for micron-thick liquid films
}

\author{
T. F. Kuech and J. O. McCaldin \\ California Institute of Technology, Pasadena, California 91125
}

(Received 3 April 1980; accepted for publication 21 April 1980)

\begin{abstract}
Suitable combinations of surface geometry and material enable a substrate to hold a thin liquid film captive on its surface. Though only at metastable equilibrium, such films can survive a moderate amount of processing. They may be suited to the growth of semiconductor singlecrystal films on amorphous substrates.
\end{abstract}

PACS numbers: $68.15 .+\mathrm{e}$

The growth of semiconductor single-crystal films on inert substrates has been the goal of many investigations ${ }^{1-6}$ in recent years. Typically the desired material is evaporated onto the substrate as an approximately micron-thick solid film, which is then subjected to zone melting or sometimes solution growth. These processes confer mechanical stability on the liquid, since the periphery of the molten zone is everywhere in contact with the solid film, which it often wets well. Thus the stretched out liquid film is usually prevented from collapsing into a more compact shape. However, the large area of contact between liquid and solid film allows many crystals from the solid to seed growth into the liquid. Resort is often made to repeated zone passes to reduce the number of crystal orientations present.

We demonstrate an alternative scheme to stabilize such liquid films. It employs contours in the substrate surface, readily obtained by lithography and other methods, which hold the liquid stretched out into a thin film. The entire film may be molten at the same time, so that the seeding protlem mentioned above is avoided. Such liquid films may be amenable to several of the established crystal growth techniques, the main novelty in the present case being the small dimensions associated with the liquid.

For semiconductor crystal growth, relatively inert substrates such as silica-based materials are preferred as well as such liquids as molten $\mathrm{Ge}, \mathrm{Ga}, \mathrm{In}, \mathrm{Sn}$, and other elements nearby in the periodic chart. These liquids generally exhibit poor wetting on the preferred substrates, i.e., liquid balls up on the substrate, exhibiting a substantial contact angle $\theta$. If portions of the substrate surface are also inclined at about angle $\theta$, however, the meniscus or surface of the liquid becomes horizontal or nearly so, as suggested in Fig. 1. Each meniscus depicted in the figure meets the well-known requirements ${ }^{7}$ of constant curvature and fixed contact angle at its termination against the substrate. ${ }^{x}$ Gravity is quite a minor force, since the liquid height is $10^{-3}$ or $10^{-4}$ of the capillary height. Also, it should be pointed out that the confined liquids shown are only at metastable equilibrium; a sphere of liquid atop the substrate has lower interfacial energy, particularly so if the line structures depicted are of great length.

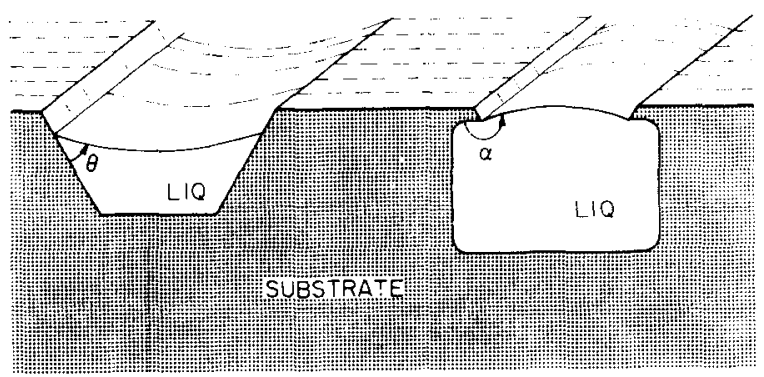

FIG. 1. Schematic of some substrate contours holding liquid captive. The trough of the left has sidewalls whose inclination is somewhat greater than the contact angle $\theta$. A concave (negative pressure) liquid surface results. The overhang structure to the right can cause the confined liquid to exhibit an effective contact angle $\alpha$ larger than the "true" contact angle $\theta$. Depending on the amount of liquid filling, either a concave or a convex (positive pressure) surface results. 


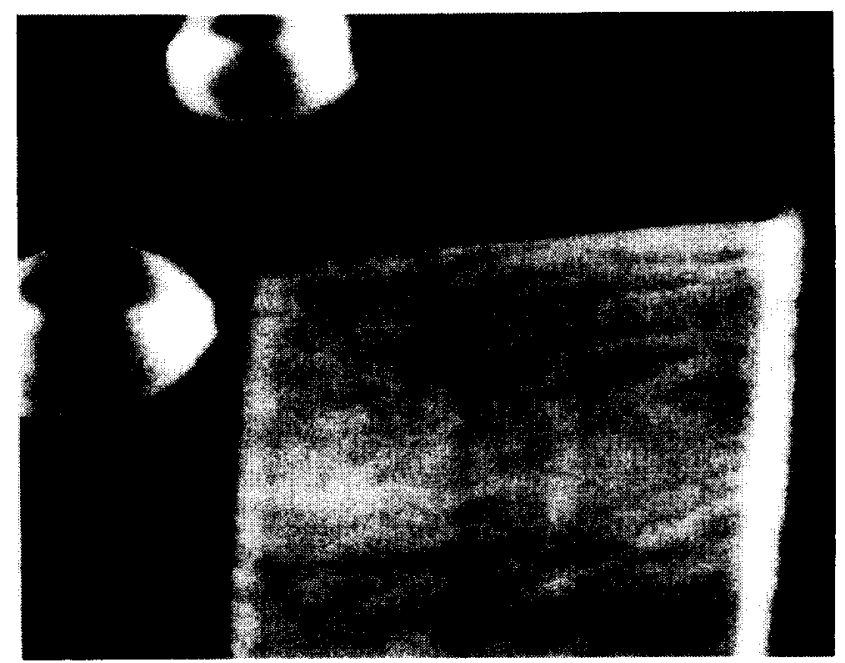

(a)

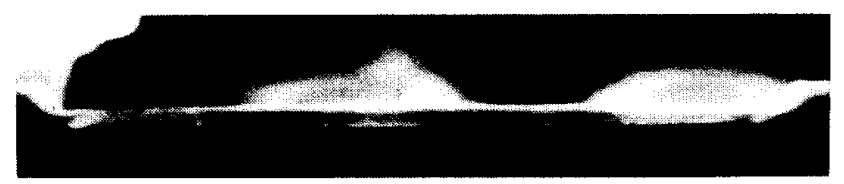

(b)

FIG. 2. Tin film captive on contoured $\mathrm{Si} / \mathrm{SiO}_{2}$ substrate. (a) Rectangular trough of sputter-cleaned $\mathrm{Si}, 30 \mu \mathrm{m}$ wide and with $54^{\circ}$-inclination sidewalls, has captured $\mathrm{Sn}$ film. On the $\mathrm{SiO}_{2}$ field $\mathrm{Sn}$ has balled up. (b) Cleaved section of same structure. Bright layer is $\mathrm{Sn}$ film $\sim 700 \mu \mathrm{m}$ thick. Oxide overhang is discernible on the right and balled-up $\mathrm{Sn}$ in the background.

Two quite different contact angles are illustrated in Fig. 1. The low-contact-angle case depicted on the left was the subject of our first experiments. Silicon substrates were used since early observations ${ }^{9}$ had indicated that ion-beamcleaned Si would form low contact angles with many liquid metals of interest. Wafers of (100) Si covered with thermally grown $\mathrm{SiO}_{2}$ were subjected to standard lithographic procedures followed by a $\mathrm{KOH}$ anisotropic etch. ${ }^{10}$ Structures similar to the truncated $\mathrm{V}$ shown in the figure were produced, but with a wide variety of horizontal and vertical dimensions. Metal was then evaporated in an ion-pumped system with a baseline pressure of $\sim 2 \times 10^{-9}$ Torr to a thickness approximating the depth of the substrate structure. In most cases some oxide had been retained on the substrate so as to provide an overhang at the periphery of each etched structure (similar to right-hand side of Fig. 1). In the present instance, the overhang serves to disconnect metal in individual structures from metal on the field so that fluid motions attendant on melting cannot couple and destroy local metastable equilibrium. Immediately after metal evaporation, specimens were positioned over a tungsten heater in the vacuum system to liquify the metal. In other instances, specimens were transferred to a hydrogen furnace for this step to reduce any oxide present. In spite of precautions, metal escaped from some of the confining structures upon melting, particularly those of very large lateral extent.

A thin metal film confined by such a substrate is shown in Fig. 2. The meniscus lies almost horizontal, being only slightly convex as judged by scanning electron microscopy
(SEM). The reason for the nearly planar meniscus is that the vertical ion beam used for sputter cleaning was shadowed by the oxide overhang; metal does not wet the upper portion of the sidewalls of the structure that are shadowed from the ion beam.

We have observed similar confined metal films of In, $\mathrm{Ga}, \mathrm{Pb}, \mathrm{Bi}$, and various binary alloys. For the elemental metals, SEM observations often display grain boundaries and sometimes texture within a crystal. Spacing between grain boundaries is almost always greater than the width of a structure, often by a large factor. For the eutectic films Au-Si and $\mathrm{Au}-\mathrm{Ge}$, dendritic structures grow upon solidification and these appear to be of single orientation in most structures, including the largest ones we have investigated, some $300 \mu \mathrm{m}$ in length. The orientation varies, apparently randomly, with respect to the substrate Si crystal.

Our more recent experiments have utilized substrates of vitreous $\mathrm{SiO}_{2}$, a substance of great interest as a containing material in crystal growth. In this case, $\theta$ ranges from $\sim 90^{\circ}$ to $\sim 135^{\circ}$ for the metals of interest, a fact probably not unrelated to the relatively inert character of the $\mathrm{SiO}_{2} /$ metal interface. The larger contact angle increases the difficulties in confining liquid, however, and more elaborate structures such as that shown on the right side of Fig. 1 become desirable.

Substrates were prepared from anisotropically etched $\mathrm{Si}$, primarily of (110) orientation. This particular orientation affords ${ }^{11}$ vertical sidewalls at certain azimuthal directions, but one necessarily obtains less steep sidewalls at other azimuths. Preparative procedures were the same as described above, except that evaporation alone was insufficient to fill structures of appreciable overhang. Resort was made to applied pressure, either by admitting inert gas to the vacuum chamber or by simple mechanical pressure applied with an optical flat, to force liquid metal to fill the structures. It is worth noting at this point that the curvature developed by the meniscus as liquid metal bulges to get through an opening of a few $\mu \mathrm{m}$ corresponds to pressures of the order of an atmosphere. Once the structures were filled, specimens were treated in Pd-purified hydrogen at temperatures of $550^{\circ} \mathrm{C}$ or higher. The confinement obtained by such structures is illustrated in Fig. 3. In other experiments employing Bi metal,

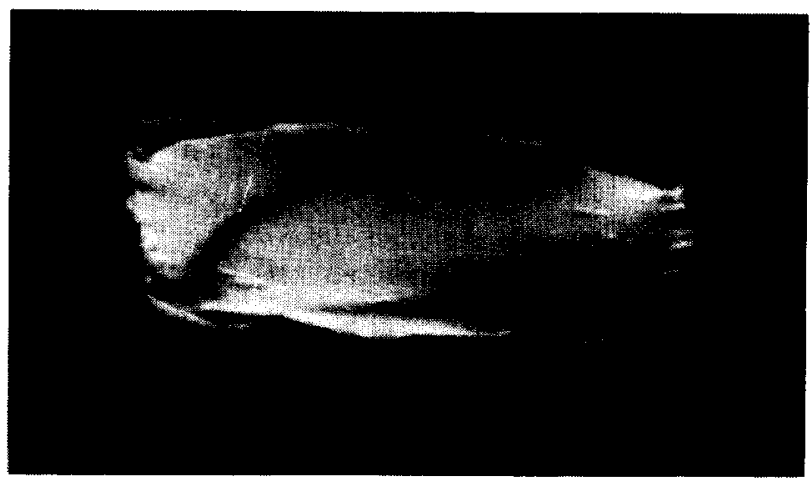

FIG. 3. Gallium captive in an all-SiO ${ }_{2}$ Structure. SEM view is inclined $70^{\circ}$ from the normal. Opening in the oxide surface is $7 \times 7 \mu \mathrm{m}$, and the extent of the oxide overhang is indicated by the lighter-shaded regions in the field. 
preferred orientation was evident in the solidified material: as judged by the fracture surfaces of cleaved specimens, the $c$ axis of the Bi crystal appears to prefer to lie along the length of a trough. Presently, we are improving specimen preparation, particularly by the use of plasma etching to achieve desired substrate contours and by the use of more than a single lithographic step.

Confined liquids such as just discussed may prove attractive for in situ crystal growth. The particular growths which we are presently investigating are from solution at low temperatures and utilize vapor species to enrich the liquid. However, our success in forming micron-thick liquid films may be of more general interest, particularly in connection with a variety of crystal growth methods.

This work was supported in part by the Joint Services Electronics Program.

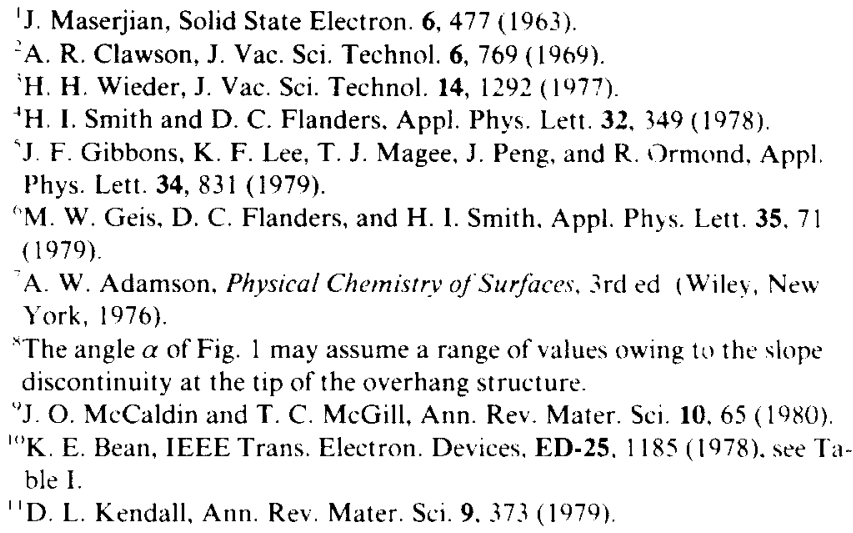

J. Maserjian, Solid State Electron. 6, 477 (1963)

A. R. Clawson, J. Vac. Sei. Technol. 6, 769 (1969).

${ }^{4}$ H. I. Smith and D. C. Flanders. Appl. Phys. Lett. 32, 349 (1978).

J. F. Gibbons, K. F. Lee, T. J. Magee, J. Peng, and R. Ormond, Appl (1979)

A. W. Adamson, Physical Chemistrv of Surfaces, 3rd ed (Wiley, New York, 1976)

The angle $\alpha$ of Fig. 1 may assume a range of values owing to the slope discontinuity at the tip of the overhang structure.

D. L. Kendall, Ann. Rev. Mater. Sci. 9. 373 (1979)

\title{
Stress wave profiles in cleaved and undamaged $\langle 111\rangle \beta-\mathrm{BaF}_{2}$ crystals at 4.0 GPa
}

\author{
Dattatraya P. Dandekar, Anthony G. Martin, and John V. Kelley \\ Army Materials and Mechanics Research Center, Watertown. Massachusetts 02172
}

(Received 21 January 1980; accepted for publication 25 April 1980)

The results of the present investigation on cleaved and undamaged $\langle 111\rangle$ crystals of $\beta-B a F_{2}$ show no signs of transformation of $\beta$ - to $\alpha-\mathrm{BaF}_{2}$ under shock compression, consistent with the idea that the transformation does not occur in the undamaged layer of $\beta-\mathrm{BaF}_{2}$. Further, the results suggest that the deformation of $(111) \beta-\mathrm{BaF}_{2}$ crystals is elastic to $4.0 \mathrm{GPa}$.

PACS numbers: $62.50 .+\mathrm{p}, 62.30 .+\mathrm{d}, 64.90 .+\mathrm{b}$

Recent shock compression studies in single crystals of $\beta-\mathrm{BaF}_{2}$ (fluorite structure, space group $\mathrm{Fm} 3 m-\mathrm{O}_{h}^{5}$ ) indicate that whereas the bulk of the crystal remains untransformed, the damaged layer resulting from shearing due to abrasive lapping does transform to its high-pressure phase, i.e., $\alpha$ $\mathrm{BaF}_{2}\left(\mathrm{PbCl}_{2}\right.$ structure space group $\left.\mathrm{Pbnm}=v^{16}\right)$ when shocked above $2.5 \mathrm{GPa}^{1,2}$ The transformation of only the damaged layer in a (111) single crystal of $\beta-\mathrm{BaF}_{2}$ and nontransformation of the remaining bulk of the single crystal were postulated to explain observed abnormal stress profiles in $\beta-\mathrm{BaF}_{2}$ in the shock compression experiments of Ref. 1 . In these profiles upon impact the stress reached a magnitude $\sigma_{1}$ and then relaxed to a stress of magnitude $\sigma_{M}\left(\sigma_{M}<\sigma_{I}\right)$ within $15 \mathrm{~ns}$. The original magnitude of stress $\sigma_{I}$ regained within a time interval of 10-34 ns, remained steady at this magnitude for the remaining recording time, approximately $480 \mathrm{~ns}$ [Fig. 1(a)].

The above postulate, consistent with then-existing shock and hydrostatic compression data on crystals of $\beta$ $\mathrm{BaF}_{2}$, also implies that shock loading experiments on $\langle 111\rangle$ single crystals of $\beta-\mathrm{BaF}_{2}$ with its face undamaged would not show the observed abnormal stress profile. The present work reports the results of both direct-impact and transmission- wave shock experiments in two undamaged (111) single crystals of $\beta-\mathrm{BaF}_{2}$ at $4.0 \mathrm{GPa}$. The results of these experiments unambiguously support this postulate.

The shock compression experiments were performed on two cleanly cleaved (111) single crystals of $\beta-\mathrm{BaF}_{2} \cdot{ }^{3}$ The crystals were disks with a diameter of $25.4 \mathrm{~mm}$ cleaved from a large crystal $\langle 111\rangle \beta-\mathrm{BaF}_{2}$ bought from Optovac, Inc. The cleaved crystals were of optical quality, free from any visual microscopic defects. The faces of these crystals were optically flat. The crystal used in the transmission experiment had both its faces optically flat and was $3 \mathrm{~mm}$ thick. The crystal used in the direct-impact experiment had only one of its faces optically flat and was $2.9 \mathrm{~mm}$ thick. The stress wave profiles were measured by means of $x$-cut quartz gauges operated in shorted mode. The gauges were $25.4 \mathrm{~mm}$ in diameter and 3.2 $\mathrm{mm}$ in thickness. The calibration coefficient determined by Graham $^{4}$ was used to determine stress in the gauge, since the guard-ring width-to-thickness ratio for the gauges exceeded 3. The details of these experiments are given in Table I. The stress wave profiles recorded by $x$-cut quartz gauges are reproduced in Fig. 1 along with the facsimile of the stress profile in $\beta-\mathrm{BaF}_{2}$ reported in Ref. 1.

The one-step wave profiles observed in the direct-im- 